\title{
Modelling of humus balance under different systems of basic tillage and soil fertilization in crop rotations
}

\author{
O. Markovska ${ }^{1 *}$, M. Maliarchuk², V. Maliarchuk ${ }^{3}$, M. Ivaniv4, V. Dudchenko ${ }^{5}$ \\ ${ }^{1}$ Kherson State Agricultural University, Stritenska Street 23, 73006, Kherson, Ukraine \\ ${ }^{2}$ Institute of Irrigated Agriculture of the National Academy of Agrarian Sciences of Ukraine, Kherson, \\ Ukraine \\ ${ }^{3}$ Ukrainian Scientific Research Institute of Forecasting and Test Equipment and Technologies for \\ Agricultural Production named after Leonid Pogorely, South Ukrainian Branch \\ ${ }^{4}$ Kherson State Agricultural University, Stritenska Street 23, 73006, Kherson, Ukraine \\ ${ }^{5}$ Institute of Rice of NAAS, Studentska Street 11, Antonivka, Skadovsk district Kherson region, 75705, \\ Ukraine \\ Corresponding authorE-mail: mark.elena@ukr.net \\ Received: 14.10.2020. Accepted 14.11.2020
}

\begin{abstract}
Over the course of 2007-2015, the department of the irrigated agriculture had been conducting research in the area of the Ingulets irrigation system on the experimental fields of the Institute of Irrigated Agriculture of the National Academy of Agrarian Sciences of Ukraine (NAAS), which were established in 1996, with the aim to develop and scientifically substantiate agroecological and technological methods for crop rotations on the irrigated lands of the Southern Steppe of Ukraine that will ensure soil fertility, increase crop productivity, economic and energetic efficiency. In 2007-2010, studies were conducted to substantiate the systems of basic tillage using different ploughing tools. The 4-field grain-row crop rotation1 included winter wheat with post-harvest cultivation of millet, corn, soybeans and spring rape. Five studied systems of basic tillage differed in methods, techniques and the depth of soil loosening. In 2011-2015, grain-row crop rotation 2 entailed soybeans, instead of spring rape seed, and winter barley with post-harvest cultivation of millet, instead of winter wheat. Five studied systems of basic tillage differed in the depth of soil loosening and non-renewable energy costs for their implementation. Experiments were performed under conditions of two organo-mineral fertilizer systems using by-products of crop rotation, fertilizer application in doses of N75P60, N97.5P60 and inoculation of soybeans with microbial compounds. Following crop rotation variants 1 and 2, a decrease in humus content within the 0-40 cm soil layer to the level of 1976, 110.2-114.4 t/ha, was observed. To prevent further decline in humus content, an optimization model was developed by capping specific weight of soybeans in short-term crop rotation $25 \%$, stubble plowing the stem and leaf mass of crops as well as applying fertilizer quantities corresponding to the expected yields. With the help of mathematical modelling, it was determined that the retention of post-harvest plant remains in soil and the application of nitrogen and phosphorus fertilizers increased humus content in soil used for growing rape by $0.3 \%$, winter wheat - by $0.7 \%$, and corn - by $0.9 \%$.
\end{abstract}

Keywords: Basic tillage; crop rotation; humus; fertilization; yield; irrigation

\section{Introduction}

Agriculture under conditions of insufficient and inconsistent soil moisture is heavily affected by weather, which makes it difficult to obtain high and stable crop yields (Balyuk et al., 2009; McCarthy, 2012; Asfaw \& Maggio, 2016; Vozhehova, 2019). Irrigation of the lands in the Southern Steppe of Ukraine guarantees their sustainable productivity regardless of climatic conditions, which are changing with an clear trend- temperatures are rising, and precipitation decreases (Vozhehova et al., 2013; Vozhehova \& Kokovikhin, 2018). Resource conservation is a primary issue when it comes to intensive technologies of growing crops. To name a few, methods and depth of basic tillage; types of fertilizers, including usage of by-products of crop rotations to maintain humus balance; microbial compounds; modern strategies of plant protection; introduction of biologically optimal irrigation regimes and particularly their integration significantly increases plant productivity by reducing financial and energy costs (Al-Kaisi \& Yin, 2003; Petrychenko \&. Panasyuk, 2009; Tararico, 2011; Lavrinenko et al., 2012; Markovska, 2017; Vozhehova et al., 2019). Abandonment of or deviation from traditional systems of agriculture necessitated a scientific justification of agro-environmental and technological measures in crop rotations on the irrigated lands of the Southern Steppe of Ukraine. Due to a reduction in cattle population and a decrease in the fraction of fodder crops, especially alfalfa, in crop rotations since the 1990s, the nature of crop rotations on the irrigate $d$ lands in Ukraine has drastically changed. Financially motivated agricultural producers implemented an intensive system of agriculture on the irrigated lands with crop rotations that are maximally saturated with soybeans, corn, winter rape and sunflower. Therefore, there is a 
need for scientific justification of short irrigated crop-rotations from the agro-ameliorative, economic, energetic and environmental perspectives.

\section{Materials and methods}

The purpose of this study was to develop and scientifically substantiate agroecological and technological measures for crop rotations on the irrigated lands of the Southern Steppe of Ukraine to ensure their fertility, increase productivity of crops, economic and energetic efficiency. Research was conducted in 2003-2017 on the experimental fields of the Institute of Irrigated Agriculture of the National Academy of Agrarian Sciences (NAAS) of Ukraine, which were established in 1996, in field crop rotations and in the area of the Ingulets irrigation system. During 2007-2010, studies were conducted to substantiate the systems of basic tillage using tillage equipment with different designs. The 4-field grain-row crop rotation1 included winter wheat with post-harvest cultivation of millet, corn, soybeans and spring rape. Five studied systems of basic tillage differed in methods, techniques and the depth of soil loosening: Variant 1:system of moldboard plowing of variable depth with the depth of soil loosening from 20-22 to $28-30 \mathrm{~cm}$ Variant 2: system of boardless plowing of basic tillage of variable depth and with the depth of soil loosening from 20-22 to $28-30 \mathrm{~cm}$ Variant 3: shallow tillage system of boardless plowing of single depth with the depth of soil loosening of $12-14 \mathrm{~cm}$ for all crops in the crop rotation

Variants 4 and 5: differential systems during which ploughing and chisel tillage alternated with shallow boardless plowing soil loosening and subsoil plowing.

In 2011-2015, grain-row crop rotation 2 entailed soybeans, instead of spring rape, and winter barley with post-harvest cultivation of millet, instead of winter wheat. Five studied systems of basic tillage differed in the depth of soil loosening and non-renewable energy costs for their implementation. Experiments were performed under conditions of two organo-mineral fertilizer systems using byproducts of crop rotation, fertilizer application in doses of N75P60; N97.5P60 and inoculation of soybean seeds with microbial compounds. Field experiments were established in accordance with the methods of research (Dospekhov, 1985), and specialized methods in the field of land reclamation and irrigated agriculture (Goryansky, 1970). The allocation of variants in the experiments was systematic, with 4 replicas and the individual plot areas of $450 \mathrm{~m}^{2}$.

The soil of the experimental fields was dark-chestnut, medium loamy, slightly saline. Its main characteristics are developed soil profile, average humus content in the $0-30 \mathrm{~cm}$ soil layer of $2.1 \%$, total nitrogen $-0.18 \%$, phosphorus $-0.16 \%$, potassium $-2.6 \%$. Weather conditions differed significantly in research year, particularly in terms of the amount of precipitation during both autumn and spring-summer vegetation periods of crops in crop rotations. In 2007 and 2012, acute deficit of precipitation also coincided with high temperatures. For the cultivation of crops in short crop rotations biologically optimal irrigation regimes were used, which are based on methodological approaches to meeting the needs of plants in water throughout the growing season at the level of $75-80 \%$ the lowest moisture content.

In the experimental part of the research, field, laboratory and analytical methods were used. To summarize the experimental data the following statistical, computational and comparative methods were used: variance, correlation and regression and variation analysis (Ushkarenko, et al., 2008; Dimov \& Bojarkina, 2019). Specialized Agrostat new software was used to model the yield of the studied crops. The method of I.V. Tyurin-Kononova enabled determination of the humus content (Vadiunina et al., 1986). Energy assessment of the developed elements of the technology of growing crops in short crop rotations on the irrigated lands was carried out according to the methods (Medvedovsky et al., 1988).

\section{Results and discussion}

We found that the yield of irrigated crops from crop rotation 1 depended on the type of basic tillage system. The highest productivity of 1 ha of crop rotation area was obtained for agricultural crops with variable depth moldboard plowing and differential systems of basic tillage in crop rotation during 2007-2010 (variants 1 and 4, 5). The maximal grain yield, 6.7 t/ha, was obtained for corn in the fifth variant, and the minimal yield, $1.2 \mathrm{t} / \mathrm{ha}$, was obtained for spring rape in the third variant. It was determined that the yield of gross energy per 1 ha of crop rotation area at the level of 82.0-82.2 GJ was provided by systems of basic tillage with variable depth and with boardless plowing (variant 1) as well as systems that differ in methods and depth of tillage (variants 4 and 5). The application of variable depth and single-depth tillage with the use of tillage tools of the chisel and disk types led to a decrease in energy intensity of the crop yield by 7.4 and $11.2 \mathrm{GJ} /$ ha, or by $9.0 \%$ and $13.6 \%$, respectively (Table 1 ).

Table 1. Crop yield and energy consumption of short crop rotation 1 depending on the systems of basic tillage under irrigation conditions, t/ha (average for 2007-2010).

\begin{tabular}{|c|c|c|c|c|c|c|c|}
\hline \multirow{2}{*}{ № } & \multirow{2}{*}{ System of basic tillage } & \multicolumn{4}{|c|}{ Crop yield, t/ha } & \multirow{2}{*}{$\begin{array}{c}\text { Energy } \\
\text { consumption of } \\
\text { yield, } \\
\text { GJ/ha }\end{array}$} & \multirow{2}{*}{$\begin{array}{l}\text { Energy growth } \\
\text { relative to control } \\
\text { GJ/ha }\end{array}$} \\
\hline & & Winter wheat & Soybean & Corn & Spring rape & & \\
\hline 1 & $\begin{array}{l}\text { Moldboard plowing of variable } \\
\text { depth }\end{array}$ & 5.0 & 2.5 & 6.2 & 2.1 & 82.2 & 0.0 \\
\hline 2 & $\begin{array}{l}\text { Boardless plowing of variable } \\
\text { depth }\end{array}$ & 5.2 & 2.0 & 5.7 & 1.6 & 74.8 & -7.4 \\
\hline 3 & Boardless plowing of single depth & 5.5 & 1.8 & 5.4 & 1.2 & 71.0 & -11.2 \\
\hline 4 & Differential-1 & 5.5 & 2.7 & 6.5 & 1.9 & 82.0 & -0.2 \\
\hline 5 & Differential-2 & 5.7 & 2.2 & 6.7 & 1.6 & 82.0 & -0.2 \\
\hline \multicolumn{2}{|c|}{ Variation coefficient. \% } & 5.4 & 16.0 & 9.5 & 26.5 & 6.8 & - \\
\hline \multicolumn{2}{|c|}{ LSD05. t/ha } & 0.21 & 0.11 & 0.25 & 0.17 & & \\
\hline
\end{tabular}


Long-term application of different systems of basic tillage in irrigated crop rotation2 (2011-2015) under conditions of two organomineral fertilizer systems using the leaf and stem mass of all crops as a fertilizer resulted in an increase in crop rotation productivity (Table 2).

Table 2. Crop yields and productivity of crop rotation 2 under irrigation conditions and different systems of basic tillage and fertilizer, $\mathrm{t} / \mathrm{ha}$ (average for 2011-2015).

\begin{tabular}{|c|c|c|c|c|c|}
\hline \multirow{2}{*}{$\begin{array}{c}\text { Tillage system } \\
\text { (factor } \mathrm{A})\end{array}$} & \multirow{2}{*}{$\begin{array}{l}\text { Fertilizer } \\
\text { (factor B) }\end{array}$} & \multicolumn{4}{|c|}{ Crops } \\
\hline & & Winter barley & Soybeans & Corn & Soybeans \\
\hline Moldboard plowing of variable depth & N975P60 & 4.3 & 3.4 & 14.3 & 3,5 \\
\hline Boardless plowing of variable depth & N975P60 & 4.2 & 3.3 & 13.9 & 3,2 \\
\hline \multirow[t]{2}{*}{ Boardless plowing of single depth } & N75P60 & 3.4 & 2.2 & 9.5 & 2,3 \\
\hline & N975P60 & 3.8 & 2.5 & 11.6 & 2,5 \\
\hline \multirow{2}{*}{ Differential-2 } & N75P60 & 3.5 & 2.6 & 12.0 & 2,6 \\
\hline & N975P60 & 4.1 & 2.9 & 14.3 & 2,9 \\
\hline Average & & 3.9 & 3.0 & 12.6 & 3.0 \\
\hline \multirow{2}{*}{$\mathrm{LSD}_{05}, \mathrm{t} / \mathrm{ha}$} & A & 0.11 & 0.16 & 0.34 & 0,19 \\
\hline & B & 0.12 & 0.11 & 0.25 & 0,10 \\
\hline Variation coefficient, \% & & 8,1 & 13.4 & 13.6 & 12.5 \\
\hline
\end{tabular}

Among all crops in crop rotation, the highest average yield was obtained for corn, $12.6 \mathrm{t} / \mathrm{ha}$, soybeans and winter barley - 3.0 and 3.9 t/ha, respectively. All crops in crop rotations provided the highest productivity when moldboard plowing (variant 1) and differential 1 (variant 4) systems of basic tillage were used. A significant decrease in yield was observed in the variant 3 (shallow tillage of single depth), in which average yields decreased for winter barley by $10.5 \%$, soybeans $-28.1 \%$; $29.0 \%$; corn - by $19.5 \%$.

Increase in the dose of mineral fertilizers from N75P60 to N97,5P60 while using the leaf and stem mass of all crops in short croprotation led to the following increases in the yield: winter barley - 13.9\%; soybeans $-10.7 \%$; corn $-21.2 \%$.

The variance analysis substantiated the difference between the degree of impact of basic tillage systems and fertilizer type on the yield of the crops in studied crop rotations under irrigation conditions. Thus, for winter barley and corn, the productivity was mostly influenced by nitrogen fertilizers, which attributed to the yield of these crops by 74.9 and $54.9 \%$, respectively. The impact of different systems of basic tillage on barley was $21.1 \%$ and $36.1 \%$ for corn.

When using fertilizers at doses of N75P60 and N97.5P60, systems of basic tillage with variable depth and boardless plowing as well as differential 2 caused a decrease in crop rotation productivity at the level of yield of grain units by 3.8 and $7.8 \%$, correspondingly, compared to the basic tillage system with variable depth and moldboard plowing (control).

Continuous use of shallow $(12-14 \mathrm{~cm})$ boardless plowing system significantly decreased the yield of all crops. In turn, crop rotation productivity at the level of yield of grain units decreased by $22.0 \%$, compared to the basic tillage system with variable depth and moldboard plowing.

Long-term studies on the dynamics of humus content in crop rotations under irrigation conditions have shown that the use of ploughing of variable depth during the first decade (1966-1976) led to a similar increase in humus content in all variants of the experiment at the level of 0.7-0.8 tons per 1 ha of crop rotation area (Fig. 1).

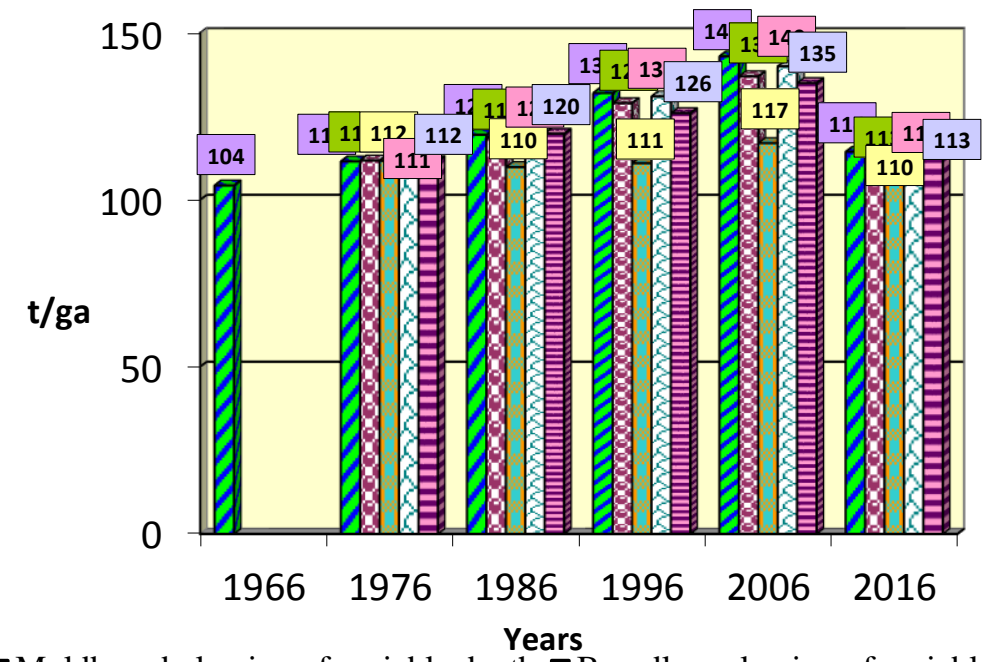

Moldboard plowing of variable depth $\mathbf{0}$ Boardless plowing of variable depth

$\square$ Boardless plowing of single depth

๑Differential-1

曰Differential-2

Fig. 1. Dynamics of humus content in the $0-40 \mathrm{~cm}$ layer of dark-chestnut soil depending on systems of basic tillage in crop rotations under irrigation conditions for the period of 1966-2016, t/ha. 
Throughout the next decade (1976-1986), with the transition to boardless plowing systems, humus content had not increased, and crop rotation productivity decreased by 3-7\%, except for the variant with variable depth of ploughing (control). Since 1986, the dose of mineral fertilizers has been increased to N157P110 and the amount of manure has been increased to 15 tons per 1 ha of crop rotation area. Consequently, the productivity of this crop rotation under irrigation conditions was $12.8 \mathrm{t} / \mathrm{ha}$ F.U. at level of the yield of fodder units in the variant ofbasic tillage system with variable depth and moldboard plowing. Under differential tillage, in which crop rotation alternated with ploughing and shallow and subsoil plowing, crop rotation productivity was 12.6-13.0 t/ha F.U.

From 1986 to 1996 and 2006, an increase in the humus content was observed in all variants of the experiment. With variable ploughing depth, its average annual increase was $1.1 \mathrm{t} / \mathrm{ha}$, while for boardless plowing of variable depth and differential tillage systems it was lower by $18.2 \%$.

During the study of two short crop rotations, crop rotation1 (2007-2010) and crop rotation 2 (2011-2016), a decrease in the humus content in the $0-40 \mathrm{~cm}$ soil layer of to the level of 1976, 110.2-114.4 t/ha, was observed. To prevent further decline in humus content, an optimization model was developed by capping specific weight of soybeans in short crop rotation $25 \%$, stubble plowing the stem and leaf mass of crops as well as applying fertilizer quantities corresponding to the expected yields.

The simulation of humus accumulation in the soil conducted using the post-harvest remains of crops in short crop rotation under different systems of basic tillage and fertilizer types shows that in an unfertilized soil a negative net growth in humus content occurs for all tillage systems, with smaller losses (- $0.16 \mathrm{t} / \mathrm{ha})$ for differential 1 tillage with subsoil plowing to a depth of $38-40 \mathrm{~cm}$ once per crop rotation and larger losses (- $0.33 \mathrm{t} / \mathrm{ha}$ ) for shallow tillage system of single depth (Fig. 2).

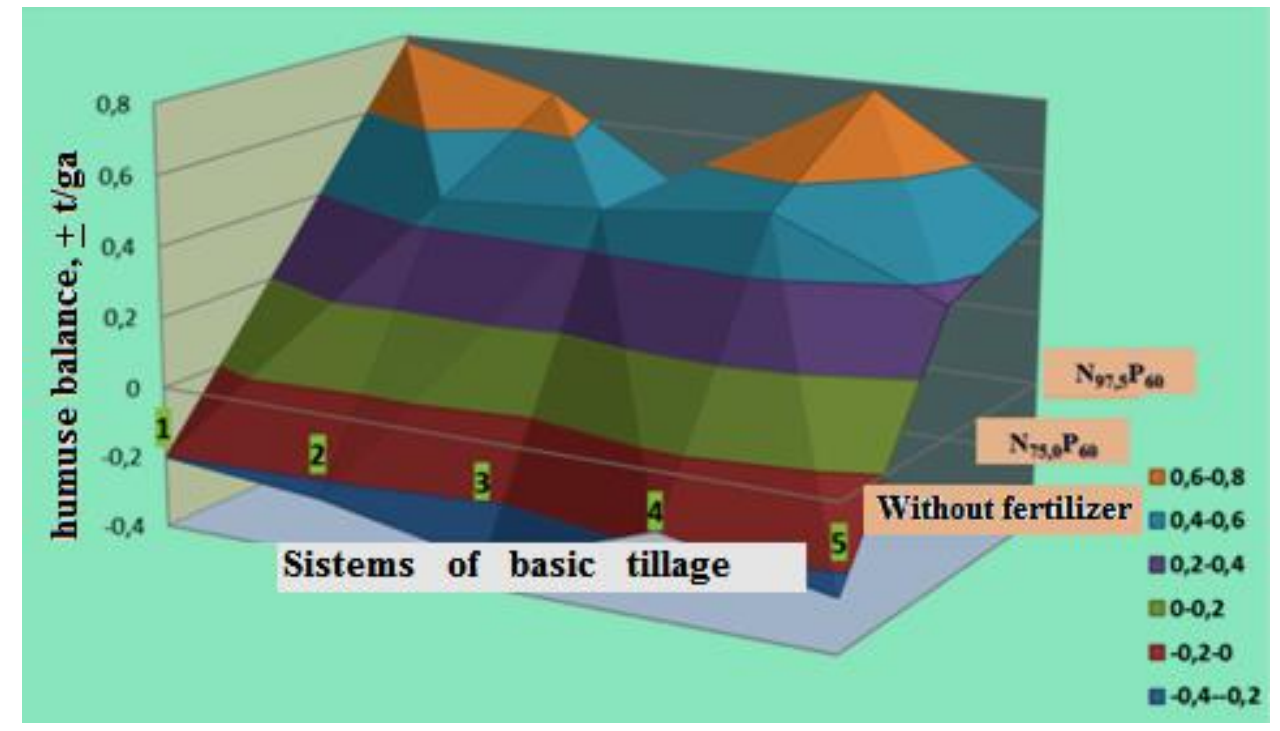

Fig. 2. Three-dimensional model of the calculated balance of humus in shortcrop rotation under irrigation conditions depending on the systems of basic tillage and fertilizer type, t/ha. 1 - moldboard plowing of variable depth; 2 - boardless plowing of variable depth; 3 - boardless plowing of single depth (shallow); 4 - differential1; 5 - differential 2.

Increase in humus content was studied on soils fertilized with N75P60 and N97.5P60. In the soil of variants of moldboard plowing systems of variable depth and differential 1, increase in humus content was $+0.78 \mathrm{t} / \mathrm{ha}$, while for boardless plowing system of variable depth it was $+0.68 \mathrm{t} / \mathrm{ha}$, or lower by $12.8 \%$. As for the single-depth (shallow) and differential 2 tillage systems, the increase in humus was also net positive. However, when compared to the control (ploughing of variable depth), it was lower by 51.3 and $38.5 \%$ and was +0.38 and +0.48 t/ha, respectively.

\section{Conclusion}

During the study of two short crop rotations, crop rotation1 (2007-2010) and crop rotation 2 (2011-2016), a decrease in the humus content in the $0-40 \mathrm{~cm}$ soil layer of to the level of 1976, $110.2-114.4 \mathrm{t} / \mathrm{ha}$, was observed. To prevent further decline in humus content, an optimization model was developed by capping specific weight of soybeans in short crop rotation $25 \%$, stubble plowing the stem and leaf mass of crops as well as applying fertilizer quantities corresponding to the expected yields.

By using mathematical modelling, it was determined that on average, for two studied crop rotations (2007-2015), the retention of post-harvest plant remains in soil and the application of nitrogen and phosphorus fertilizers increased humus content in soil used for growing rapeseed by $0.3 \%$, winter wheat - by $0.7 \%$, and corn - by $0.9 \%$. Cultivation of soybeans in crop rotation has led to a negative net increase in humus content, which must be considered in crop rotation planning and development of ecological and reclamation measures to preserve and improve soil fertility.

\section{References}

Al-Kaisi, M.M., \& Yin, X. (2003). Effects of nitrogen rate, irrigation rate, and plant population on corn yield and water use efficiency. Agronomy Journal, 95(6), 1475-1482.

Asfaw, S., Maggio, G. (2016).Gender integration into climate-smart agriculture.Tools for data collection and analysis for policy and research.Food and Agriculture Organization of the United Nations Rome.

Balyuk, S.A., Romashchenko, M.I., \& Stashuk, V.A. (2009). Scientific bases of protection and rational use of irrigated land. Kyiv: Agrarian science. (in Ukrainian). 
Dimov, O.M., \& Bojarkina, L.V.(2019). Method correlation and regression analysis as the tool of assessment of efficiency of technologies of cultivation of crops on the irrigated lands. Zroshuvane zemlerobstvo, 71, 44 - 52. https://doi.org/10.32848/01352369.2019.71.10

Dospekhov, B.A. (1985). Field experiment technique. Moscow. (in Russian).

Goryansky, M.M. (1970). Methodology of field experiments on irrigated lands. Kyiv: Urozhay (in Ukrainian).

Lavrinenko, Y.O., Kokovikhin, S.V., Tishchenko, O.D. (2012). Optimization of soil water regime in the steppe of Ukraine in the cultivation of crops using laboratory equipment. Bulletin of steppe agriculture, 1, 35-41.

Markovska, O.Ye. (2017). Economic and energy efficiency of growing crops in irrigated row crop rotation under different systems of basic tillage and fertilizer. Scientific Bulletin of NULES of Ukraine, 238, 72-77.

McCarthy, N. (2011). Understanding agricultural households' adaptation to climate change and implications for mitigation: land management and investment options. Integrated Surveys on Agriculture. Washington D.C., USA: LEAD Analytics Inc.

Medvedovsky, O.K., Ivanenko, P.I. (1988). Energy analysis of intensive technologies in agricultural production. Kyiv: Urozhay. (in Ukrainian).

Petrychenko, V.F., Panasyuk, Ya. (2009). Modern systems of agriculture of Ukraine. Vinnytsia. (in Ukrainian).

Tararico, Y.O. (2011). Energy-saving agroecosystems. Assessment and rational use of agro-resource potential of Ukraine.Recommendations on the example of the Steppe and Forest-Steppe. Kyiv: DIA. (in Ukrainian).

Ushkarenko, V.O., Nikishenko, V.L., Goloborodko, S.P., \& Kokovihin, S.V, (2008). Disperse and correlation analysis in agriculture and plant science: textbook. Herson, Aylant.

Vadiunina, A.F., \& Korchagina, Z.A. (1986). Methods of study of physical properties of soils. Moscow (in Russian).

Vozhegova, R.A., Goloborodko, S.P., Granovska, L.M., Sakhno, G.V. (2013). Irrigation in Ukraine: current realities and prospects of revival. Irrigated agriculture, 60, 3-12.

Vozhegova, R.A., Kokovikhin, S.V. (2018). Irrigated lands - the guarantor of food security of Ukraine in the conditions of climate change. Bulletin of agrarian science, 96 (11), $28-34$.

Vozhehova, R. (2019). Irrigation is the main element of modern agricultural technologies in the conditions of the Southern Steppe of Ukraine. Bulletin of Agricultural Science, 97(11), 67-74.

Vozhehova, R.A., Maliarchuk, M.P., Biliaieva, I.M., Markovska, O.Ye., Maliarchuk, A.S., Tomnytskyi, A.V., Lykhovyd, P.V., \& Kozyrev, V.V. (2019). The effect of tillage system and fertilization on corn yield and water use efficiency in irrigated conditions of the South of Ukraine. Biosystems Diversity, 27(2), 125-130. https: //doi:10.15421/011917

\section{Citation:}

Markovska, O., Maliarchuk, M., Maliarchuk, V., Ivaniv, M., Dudchenko, V. (2020). Modelling of humus balance under different systems of basic tillage and soil fertilization in crop rotations. Ukrainian Journal of Ecology, 1 145), 291-295.

(cc) EY This work is licensed under a Creative Commons Attribution 4.0. License 